\title{
Desenvolvimento vegetativo de duas cultivares de oliveira na fase de muda
}

\author{
Vegetative development of two olive cultivars in seedling phase
}

\author{
Priscila Maria Martins Lisboa ${ }^{\mathrm{I}^{*}}$ Fabrina Bolzan Martins ${ }^{\mathrm{II}}$ Maria Inês Nogueira Alvarenga ${ }^{\mathrm{II}}$ \\ João Vieira Neto ${ }^{\mathrm{III}}$ Diogo da Fonseca Reis ${ }^{\mathrm{IV}}$
}

\section{RESUMO}

O desenvolvimento de plantas, influenciado pela temperatura do ar, pode ser estimado através do conceito de filocrono, definido como o intervalo de tempo entre o surgimento sucessivo de folhas em uma haste, sendo o tempo expresso em ${ }^{\circ} \mathrm{C}$ dia e o filocrono em ${ }^{\circ} \mathrm{C}$ dia folha ${ }^{-1}$. $\mathrm{O}$ objetivo deste estudo foi avaliar o desenvolvimento de duas cultivares de oliveira durante a fase de muda, em diferentes épocas de aclimatação, utilizando o conceito de filocrono. $O$ experimento foi conduzido na Fazenda Experimental da Epamig, em Maria da Fé, sul de Minas Gerais, Brasil. O delineamento utilizado foi o inteiramente casualizado em esquema fatorial $2 \times 5$, com duas cultivares ('MGS ASC315'e 'Arbequina'), cinco épocas de aclimatação (maio, junho, julho, agosto e setembro de 2010) e 15 repetições. O filocrono foi estimado pelo inverso do coeficiente angular da regressão linear entre o número de folhas emitidas (NF) e a soma térmica acumulada (STa). O filocrono em 'MGS ASC315' foi de $14,7^{\circ} \mathrm{C}$ dia folha ${ }^{-1}$ (época 1), $31,7^{\circ} \mathrm{C}$ dia folha ${ }^{-1}$ (média das épocas 2,3 e 4) e $60,2^{\circ} \mathrm{C}$ dia folha $^{-1}$ (época 5). O filocrono em 'Arbequina' foi de $17,3^{\circ} \mathrm{C}$ dia folha ${ }^{-1}$ (média das cinco épocas de aclimatação, uma vez que não apresentou diferença significativa entre as épocas). Nas épocas de aclimatação 3, 4 e 5, houve diferença do filocrono entre as cultivares, sendo que o menor filocrono foi para a cultivar 'Arbequina'. Nas épocas 1 e 2, não houve diferenças significativas entre as cultivares.

Palavras-chave: Olea europaea L., filocrono, soma térmica, temperatura do ar.

\section{ABSTRACT}

Plants development, influenced by air temperature, can be estimated through the concept of phyllochron, defined as the time interval between the appearance of successive leaves on a stem, being the time expressed in ${ }^{\circ} \mathrm{C}$ day and the phyllochron in ${ }^{\circ} \mathrm{C}$ day leaf ${ }^{1}$. The objective of this study was to evaluate the development of two olive cultivars during the seedling phase at different acclimation dates, using the concept of phyllochron. The experiment was carried in the experimental area of the Agricultural Research Corporation of Minas Gerais, Maria da Fé, south of Minas Gerais, Brazil. The experimental design was completely randomized with two cultivars (MGS 'ASC315' and 'Arbequina'), five acclimation date (May, June, July, August and September 2010) and 15 repetitions. The phyllochron was estimated by the inverse of the slope of the linear regression between leaves number (NF) and accumulated thermal time (STa). The phyllochron in 'MGS ASC315' was $14,7^{\circ} \mathrm{C}$ day leaf ${ }^{1}$ (date 1), $31,7^{\circ} \mathrm{C}$ day leaf ${ }^{-1}$ (average of dates 2, 3 and 4) and $60,2^{\circ} \mathrm{C}$ day leaf ${ }^{-1}$ (date 5). The phyllochron in 'Arbequina' was $17,3^{\circ} \mathrm{C}$ day leaf ${ }^{-1}$ (average of five acclimation dates, due not statistically difference among dates). In acclimation dates 3, 4 and 5, not statistically difference between cultivars, and the smallest phyllochron for 'Arbequina'. In acclimation dates 1 and 2, were not statistically different between cultivars.

Key words: Olea europaea L., phyllochron, thermal time, air temperature.

\section{INTRODUÇÃO}

A família Oleaceae abrange cerca de trinta gêneros, entre eles o gênero Olea. A espécie mais conhecida desse gênero é a oliveira (Olea europaea L.), cuja origem possivelmente seja a Síria, o Líbano e Israel (VIEIRA NETO et al., 2008).

\footnotetext{
IPrograma de Pós-graduação em Meio Ambiente e Recursos Hídricos, Universidade Federal de Itajubá (UNIFEI), 37500-903, Itajubá, MG, Brasil. E-mail: priscilammlisboa@gmail.com. *Autor para correspondência.

"Instituto de Recursos Naturais (IRN), UNIFEI, Itajubá, MG, Brasil.

IIIEstação Experimental de Ituporanga da EPAGRI, Ituporanga, SC, Brasil.

${ }^{\text {IV }}$ Curso de Engenharia Ambiental, UNIFEI, Itajubá, MG, Brasil.
} 
A área cultivada de oliveira no mundo corresponde a aproximadamente 10,6 milhões de hectares e o seu cultivo está relacionado, principalmente, à produção de azeite, sendo que, nos últimos 20 anos, a produção mundial de azeite aumentou de 1,45 milhão de toneladas (1990/1991) para 3,08 milhões de toneladas (2010/2011), representando um aumento de $112 \%$ (INTERNATIONAL OLIVE COUNCIL, 2011). No Brasil, entretanto, os plantios comerciais de oliveira são recentes e a produção ainda não é suficiente para abastecer o mercado nacional, tornando o país um dos maiores importadores de azeitona e azeite do mundo, sendo Argentina, Espanha e Portugal os principais fornecedores (VIEIRA NETO et al., 2008).

Com o aumento do consumo de produtos da oliveira e pela atual ênfase dada no tratamento de várias doenças, tornou-se necessário elevar a produtividade da oliveira em todo o mundo. Para isso, é importante realizar estudos que relacionem o desenvolvimento da oliveira com variáveis ambientais. Esse tipo de estudo é importante, principalmente, em regiões que apresentam diferentes condições edafoclimáticas das regiões de origem e cultivo da oliveira, já que pode ter seu desenvolvimento afetado negativamente, quando introduzida fora do seu habitat natural (OLIVEIRA et al., 2012).

A temperatura do ar tem se apresentado como a variável ambiental que mais influencia no desenvolvimento das plantas (MARTINS et al., 2007; PAULA\& \&TRECK, 2008; ROSAetal., 2009). Umamaneira tradicional de relacionar o desenvolvimento vegetal com a temperatura do ar é através do conceito de filocrono, definido como o intervalo de tempo, em ${ }^{\circ} \mathrm{C}$ dia, entre o surgimento sucessivo de folhas em uma haste, com unidade ${ }^{\circ} \mathrm{C}$ dia folha ${ }^{-1}$ (XUE et al., 2004). O número de folhas emitidas (NF) é utilizado no conceito de filocrono por ser uma variável importante na quantificação do desenvolvimento vegetal (ROSA et al., 2009).

Trabalhos de pesquisa utilizando o conceito de filocrono foram realizados para culturas perenes, como eucalipto (MARTINS et al., 2007), e principalmente para culturas anuais, como trigo (ROSA et al., 2009), batata (DELLAI et al., 2005), tomate (PIVETTA et al., 2007), mandioca (SCHONS et al., 2007) e milho(STRECK et al., 2009). Com relação à oliveira, estudos sobre o seu desenvolvimento ainda são escassos em regiões fora do seu habitat de origem. No entanto, esse tipo de informação auxilia no conhecimento do desenvolvimento das plantas de oliveira e pode ser importante na implantação e manejo da cultura.

O objetivo deste trabalho foi avaliar o desenvolvimento de duas cultivares de oliveira, 'MGS ASC315’ e ‘Arbequina', durante a fase de muda, em diferentes épocas de aclimatação, utilizando o conceito de filocrono.

\section{MATERIAL E MÉTODOS}

O experimento foi conduzido na Fazenda Experimental de Maria da Fé (FEMF), pertencente à Empresa de Pesquisa Agropecuária de Minas Gerais (Epamig), em Maria da Fé, MG (latitude: 22¹8'29' S; longitude: 45²2’31' W; e altitude: $1.276 \mathrm{~m}$ ). O clima do local, segundo a classificação de Köppen, é do tipo Cwb, subtropical de altitude com invernos secos e verões chuvosos de temperaturas brandas (VIEIRA NETO et al., 2011).

O delineamento utilizado foi o inteiramente casualizado, organizado em esquema fatorial 2x5, com duas cultivares ('MGS ASC315' e 'Arbequina'), cinco épocas de aclimatação (maio, junho, julho, agosto e setembro de 2010) e 15 repetições.

Cada época de aclimatação foi instalada em intervalos de aproximadamente trinta dias. A época 1 foi instalada em 04/05/2010; a época 2, em 02/06/2010; a época 3, em 12/07/2010; a época 4, em 06/08/2010; e a época 5, em 10/09/2010. O intuito de utilizar cinco épocas de aclimatação foi expor as plantas a diferentes condições meteorológicas e, assim, estimar o filocrono com maior exatidão (MARTINS et al., 2007; ROSA et al., 2009).

Cada repetição foi constituída de uma muda de oliveira ausente de brotação e proveniente do enraizamento de estaca semilenhosa, segundo a metodologia de OLIVEIRA et al. (2009) e PIO et al.(2005), sendo plantada em saco plástico de polietileno com capacidade de $2 \mathrm{dm}^{3}$, preenchido com substrato constituído de terra e composto orgânico comercial $\left(\right.$ Provaso $\left.^{\circledR}\right)$, na proporção de 1:1 $\left(\mathrm{v} \mathrm{v}^{-1}\right)$. Cada $\mathrm{m}^{3}$ de substrato foi enriquecido com $5 \mathrm{~kg}$ de superfosfato simples (18dag kg ${ }^{-1}$ de $\mathrm{P}_{2} \mathrm{O}_{5}$ ), $1 \mathrm{~kg}$ de cloreto de potássio (58dag kg ${ }^{-1}$ de $\mathrm{K}_{2} \mathrm{O}$ ) e 2,5kg de calcário dolomítico (PRNT $100 \%)$. Os sacos plásticos foram envolvidos com papel jornal a fim de minimizar a absorção da radiação solar e, assim, evitar o aumento de temperatura do substrato, o que poderia afetar o desenvolvimento das mudas.

O número de folhas emitidas pelas estacas enraizadas (NF) foi contado numa frequência de uma vez por semana. Para a sua contagem, cada brotação recebeu um anel colorido para fins de identificação. A contagem foi iniciada quando havia uma folha visível, considerando-se como folha visível aquela com, no mínimo, 1,0cm de comprimento. A fase de muda foi finalizada quando cada repetição atingiu 20 folhas visíveis, no mínimo (MARTINS et al., 2007).

Os dados diários de temperatura mínima e máxima do ar foram obtidos de uma estação 
meteorológica convencional pertencente ao Instituto Mineiro de Gestão das Águas (IGAM) e localizada na FEMF a, aproximadamente, $100 \mathrm{~m}$ do local de instalação do experimento.

O método utilizado para o cálculo da soma térmica foi o proposto por ARNOLD (1960), que considera a média aritmética das temperaturas mínimas e máximas diárias do ar menos a temperatura base inferior da cultivar: $S T d=((T M+T m) / 2)-T b .1$ dia; se $(T M+T m) / 2 \leq \mathrm{Tb}$, então STd=0 (Equação 1$)$, em que: $\mathrm{STd}=$ soma térmica diária $\left({ }^{\circ} \mathrm{C}\right.$ dia $), \mathrm{TM}=$ temperatura máxima diária do $\operatorname{ar}\left({ }^{\circ} \mathrm{C}\right), \mathrm{Tm}=$ temperatura mínima diária do $\operatorname{ar}\left({ }^{\circ} \mathrm{C}\right)$ e $\mathrm{Tb}=$ temperatura base inferior da cultivar $\left({ }^{\circ} \mathrm{C}\right)$. A temperatura base inferior usada no cálculo da soma térmica para ambas as cultivares de oliveira foi de 8,5 C (MELO-ABREU et al., 2004). Para o cálculo da soma térmica acumulada (STa), utilizou-se o somatório das somas térmicas diárias (STd) a partir da data de instalação de cada época de aclimatação no campo, ou seja, $\mathrm{STa}=\sum \mathrm{STd}$.

Para cada repetição, em cada cultivar e época de aclimatação, foi ajustada uma regressão linear simples entre NF e STa a partir da data de instalação de cada época no campo, ou seja: $\mathrm{NF}=\mathrm{a} . \mathrm{STa}+\mathrm{b}$ (Equação 2), em que: $\mathrm{a}=$ coeficiente angular, $\mathrm{b}$ = coeficiente linear $\mathrm{e}$ $\mathrm{STa}=\sum \mathrm{STd}\left({ }^{\circ} \mathrm{C} \mathrm{dia}^{-1}\right)$. Para $\mathrm{o}$ ajuste das regressões, foi utilizado o programa estatístico Statgraphics Plus 2.1. $\mathrm{O}$ valor do filocrono foi obtido pelo inverso do coeficiente angular dessa regressão (Equação 2), ou seja, Filocrono = 1/a (XUE et al., 2004).

A análise de variância dos valores de filocrono para as duas cultivares e cinco épocas de aclimatação foi feita através do programa estatístico Sisvar $^{\circledR}$ (FERREIRA, 2011), comparando-se as médias do filocrono das 15 repetições pelo teste de SCOTT \& KNOTT (1974), a 5\% de probabilidade.

\section{RESULTADOS E DISCUSSÃO}

Durante as cinco épocas de aclimatação, houve grande variação nas condições meteorológicas (Tabela 1), as quais afetaram a velocidade de emissão de folhas e, assim, o valor do filocrono, sendo importantes no estudo de desenvolvimento da oliveira. O menor valor absoluto da temperatura mínima do ar foi de $-1,3^{\circ} \mathrm{C}$ (durante a época 4) e o maior valor absoluto da temperatura máxima do ar foi de $31,4^{\circ} \mathrm{C}$ (durante a época 5). A época de aclimatação com a menor temperatura média do ar foi a época 1 , com temperatura média de $15,2^{\circ} \mathrm{C}$, enquanto a época de aclimatação que obteve a maior temperatura média do ar foi a época 5, com temperatura média de $19,3^{\circ} \mathrm{C}$.
Tabela 1 - Médias das temperaturas mínima, média e máxima diárias do ar $\left({ }^{\circ} \mathrm{C}\right)$, nas diferentes épocas de aclimatação (E1 a E5), correspondentes ao período que se estende da data de instalação de cada época até a última observação do NF. Maria da Fé, MG, 2010.

\begin{tabular}{lccc}
\hline \multirow{2}{*}{ Época de aclimatação } & \multicolumn{3}{c}{------Temperatura do ar $\left({ }^{\circ} \mathrm{C}\right)--------}$. \\
& Mínima & Média & Máxima \\
\hline E1 & 6,8 & 15,2 & 23,7 \\
E2 & 7,6 & 15,8 & 24,1 \\
E3 & 9,2 & 17,1 & 25,0 \\
E4 & 9,7 & 17,6 & 25,5 \\
E5 & 12,7 & 19,3 & 26,0 \\
\hline
\end{tabular}

A relação entre o número de folhas emitidas pelas estacas enraizadas (NF) e a soma térmica acumulada (STa) foi linear, com coeficiente de determinação $\left(\mathrm{r}^{2}\right)$ acima de 0,72 para ambas as cultivares avaliadas, em todas as épocas de aclimatação (Figura 1). Esse resultado indica que a temperatura do ar foi a variável ambiental que mais influenciou na emissão de folhas das duas cultivares de oliveira, podendo a regressão linear ser considerada um método apropriado para estimar o desenvolvimento através do conceito de filocrono, como tem sido observado para culturas agrícolas (DELLAI et al., 2005; PIVETTA et al., 2007; SCHONS et al., 2007; STRECK et al., 2009) e algumas florestais (MARTINS et al., 2007), medicinais (KOEFENDER et al., 2008) e ornamentais (FAGUNDES et al., 2007).

A análise de variância mostrou que houve diferença significativa a 5\% de probabilidade para os fatores cultivar e época de aclimatação e também, para a interação dos fatores, indicando que o filocrono entre as cultivares diferiu, dependendo da época de aclimatação.

O filocrono variou entre as cultivares apenas nas épocas de aclimatação 3, 4 e 5, nas quais o menor filocrono foi da Arbequina (Tabela 2). Isso significa que a Arbequina necessita de menor quantidade de energia $\left({ }^{\circ} \mathrm{C}\right)$ que a cultivar MGS ASC315 para emitir uma folha nas épocas 3, 4 e 5. Nas épocas de aclimatação 1 e 2, o filocrono não variou entre as cultivares (Tabela 2), indicando que, nessas épocas, tanto 'MGS ASC315' quanto ‘Arbequina’ necessitaram da mesma quantidade de energia térmica $\left({ }^{\circ} \mathrm{C}\right.$ dia) para emitir uma folha.

O filocrono variou entre as épocas de aclimatação apenas para a cultivar 'MGS ASC315', para a qual o filocrono teve a sequência E1 $\angle \mathrm{E} 2=\mathrm{E} 3=\mathrm{E} 4<\mathrm{E} 5$ (Tabela 2). Assim, os menores valores de filocrono ocorreram durante o período de temperaturas mais baixas (época 1) e os maiores valores durante o período 


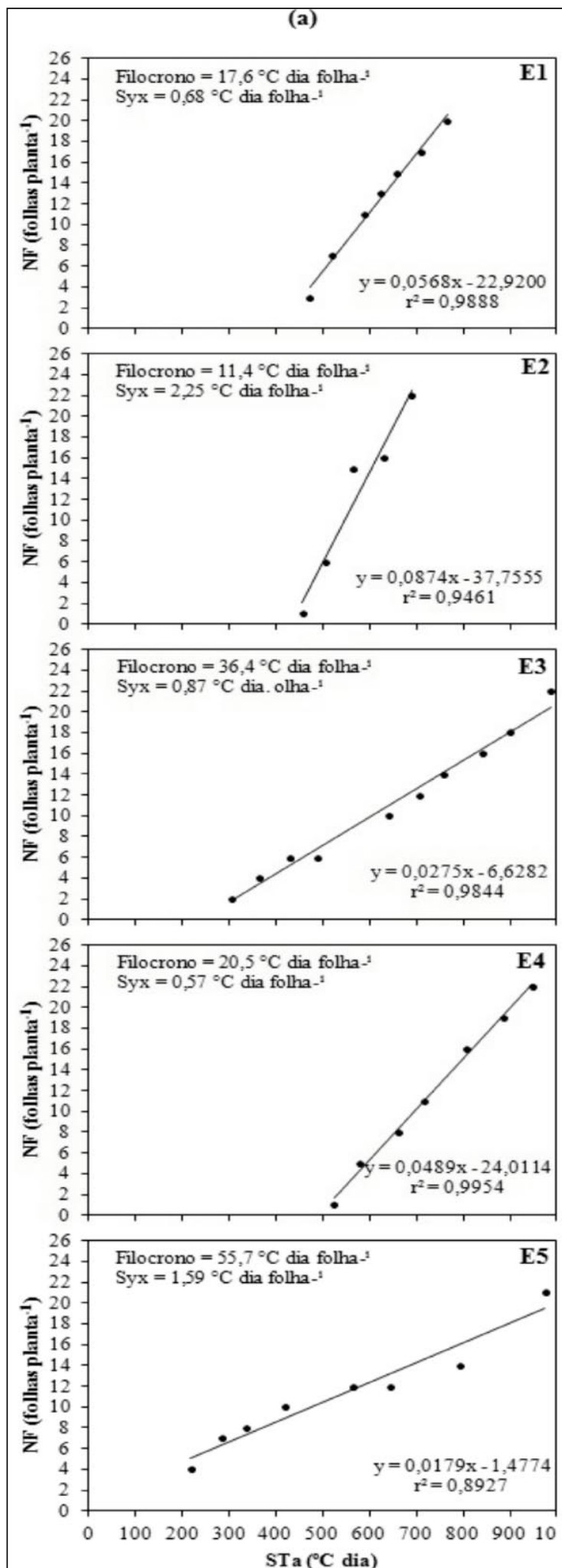

(b)
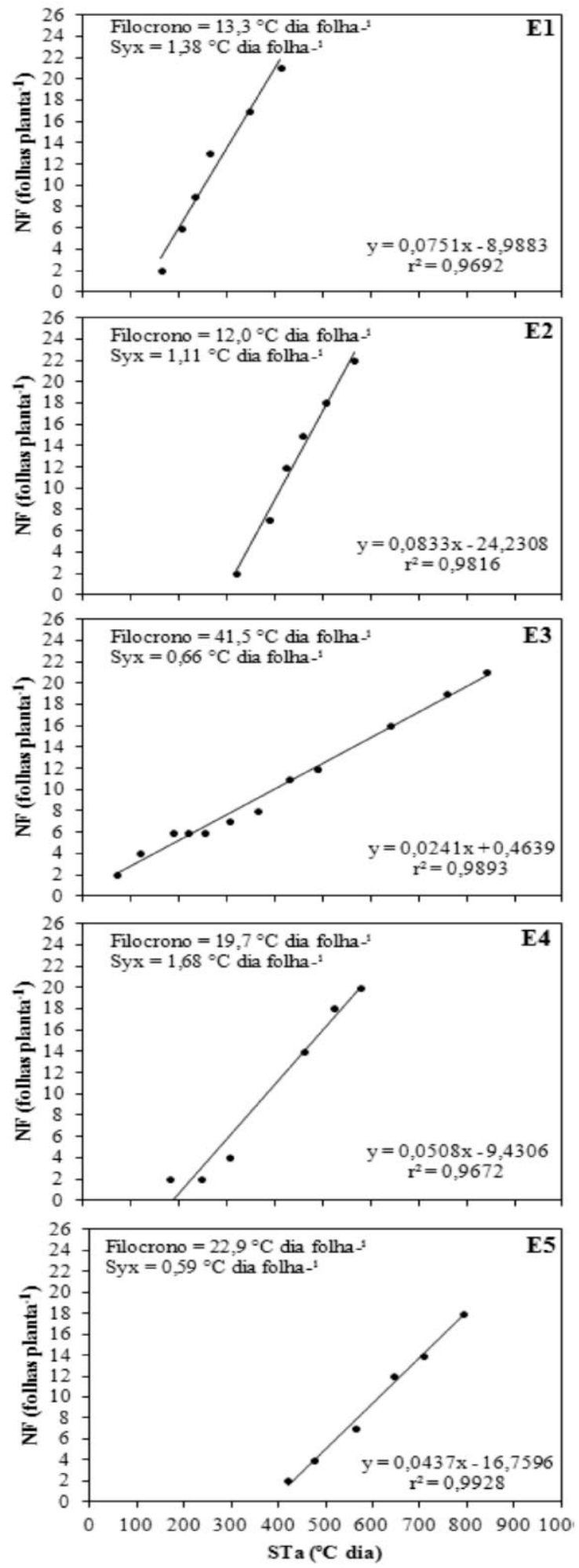

Figura 1 - Relação entre o número de folhas emitidas (NF) e a soma térmica acumulada (STa) utilizada para a estimativa do filocrono para as cultivares 'MGS ASC315' (a) e ‘Arbequina' (b), nas cinco épocas de aclimatação (E1=1; E2=2; E3=3; E4=4, e E5=5). Os dados de cada gráfico correspondem a uma repetição (saco plástico com uma estaca semilenhosa enraizada). Syx é o erro padrão da estimativa e $\mathrm{r}^{2}$ é o coeficiente de determinação. Maria da Fé, MG, 2010. 
Tabela 2 - Médias do filocrono $\left({ }^{\circ} \mathrm{C}\right.$ dia folha $\left.{ }^{-1}\right)$ para as duas cultivares de oliveira nas cinco épocas de aclimatação (E1 a E5). Maria da Fé, MG, 2010.

\begin{tabular}{lccccc}
\hline \multirow{2}{*}{ Cultivares } & \multicolumn{1}{c}{ E1 } & E2 & E3 & E4 & E5 \\
& $14,7 \mathrm{Ca}$ & $28,9 \mathrm{Ba}$ & $33,1 \mathrm{Ba}$ & $33,0 \mathrm{Ba}$ & $60,2 \mathrm{Aa}$ \\
\hline 'MGS ASC315' & $12,3 \mathrm{Aa}$ & $18,3 \mathrm{Aa}$ & $18,9 \mathrm{Ab}$ & $16,7 \mathrm{Ab}$ & $19,6 \mathrm{Ab}$ \\
'Arbequina' & & & & \\
\hline
\end{tabular}

*Médias seguidas pela mesma letra, maiúscula na linha e minúscula na coluna, não diferem significativamente entre si pelo teste de Scott \& Knott (1974), a 5\% de probabilidade.

de temperaturas mais elevadas (época 5). Essa tendência de aumento do filocrono com a elevação da temperatura do ar também foi observada em mandioca (SCHONS et al., 2007) e calêndula (KOEFENDER et al., 2008). Para a cultivar Arbequina, o filocrono não variou entre as épocas de aclimatação (Tabela 2).

As razões para menores valores de filocrono em oliveira ocorrerem nas épocas de temperaturas mais amenas e os maiores valores nas de temperaturas mais quentes, em 'MGS ASC315', ainda precisam ser elucidadas, já que é comum ocorrer o oposto ao observado neste estudo (maior filocrono em épocas mais frias e menor filocrono em épocas mais quentes).

Talvez o fotoperíodo possa ter um papel importante nessa resposta, afetando a velocidade de emissão de folhas (PAULA\& STRECK, 2008). No entanto, para verificar a influência do fotoperíodo no filocrono, é necessário realizar um experimento com um maior número de épocas de aclimatação. Outro ponto que pode ter influenciado nos valores de filocrono foi o método de cálculo da soma térmica utilizado no estudo, o qual considera apenas a temperatura base inferior da cultura. Outros métodos de cálculo de soma térmica que consideram a temperatura ótima e a temperatura base superior poderiam contribuir com respostas diferentes e, provavelmente, mais satisfatórias para a estimativa do filocrono (ROSA et al., 2009).

Essa última questão pode ser reforçada analisando a média aritmética das temperaturas médias durante a época de aclimatação 1 (desde a instalação até a finalização) para 'MGS ASC315', em que houve o maior desenvolvimento para a cultivar 'MGS ASC315', que pode ser um indício da temperatura ótima (Tot) de $14,7^{\circ} \mathrm{C}$ para a cultivar. Nas épocas de aclimatação 2, 3, 4 e 5, as temperaturas médias do ar foram mais elevadas que o indício da Tot, sendo que, na época 5, isso ocorreu em praticamente todos os dias. Assim, a inclusão da Tot no método de cálculo da soma térmica poderia reduzir os valores de STa das épocas 2, 3, 4, e principalmente da época 5, que apresentaram temperaturas do ar superiores ao indício da Tot e, consequentemente, influenciar nos valores estimados do filocrono.

Já a cultivar 'Arbequina' apresentou um indício da Tot de $16,1^{\circ} \mathrm{C}$. Esse valor foi obtido pela média aritmética das temperaturas médias das cinco épocas de aclimatação, já que não houve diferença significativa entre os valores de filocrono para a cultivar ‘Arbequina' nas cinco épocas de aclimatação. Esse maior indício de Tot da cultivar ‘Arbequina’ em relação à cultivar 'MGS ASC315' sugere que a 'Arbequina' se desenvolve satisfatoriamente em temperaturas ligeiramente superiores a 'MSG ASC315', já que as temperaturas médias do ar registradas durante as cinco épocas de aclimatação não foram inferiores a $15,2^{\circ} \mathrm{C}$, e sugere também que a 'Arbequina' se desenvolve tanto em épocas com temperaturas do ar mais amenas ou mais quentes, quanto em épocas com temperaturas do ar próximas à Tot $\left(16,1^{\circ} \mathrm{C}\right)$, quando se desenvolve plenamente. Além disso, a inserção de um valor maior de Tot em outros métodos de cálculo da soma térmica, poderá não influenciar significativamente na STa da cultivar 'Arbequina', uma vez que a Tot dessa cultivar é ligeiramente superior à cultivar 'MGS ASC 315', o que indica que o método de soma térmica utilizado neste estudo foi coerente para a cultivar 'Arbequina'.

O fato de não ter havido diferença significativa do filocrono para a cultivar 'Arbequina' nas cinco épocas de aclimatação (Tabela 2) é interpretado como um indicativo de que o fotoperíodo não afeta a velocidade de emissão de folhas, uma vez que, durante as cinco épocas de aclimatação, as plantas se desenvolveram de forma semelhante.

Para a cultivar 'MGS ASC315', o filocrono foi de $14,7^{\circ} \mathrm{C}$ dia folha ${ }^{-1}$ (época 1 ), $31,7^{\circ} \mathrm{C}$ dia folha ${ }^{-1}$ (épocas 2, 3 e 4) e $60,2^{\circ} \mathrm{C}$ dia folha ${ }^{-1}$ (época 5). Para a cultivar 'Arbequina', o filocrono adotado foi de $17,3^{\circ} \mathrm{C}$ dia folha-1 ${ }^{-1}$ édia das cinco épocas de aclimatação, uma vez que não apresentou diferença significativa entre as épocas). MARTINS et al. (2007) encontraram valores semelhantes aos da cultivar 'MGS ASC315', nas épocas de aclimatação 2, 3 e 4, para as espécies

Ciência Rural, v.42, n.9, set, 2012. 
Eucalyptus grandis $\left(32,0^{\circ} \mathrm{C}\right.$ dia folha $\left.{ }^{-1}\right)$ e Eucalyptus saligna $\left(30,7^{\circ} \mathrm{C}\right.$ dia folha $\left.{ }^{-1}\right)$. Os valores de filocrono da cultivar 'Arbequina' foram semelhantes aos valores encontrados para batata $\left(19,2^{\circ} \mathrm{C}\right.$ dia folha ${ }^{-1}$ a $22,9^{\circ} \mathrm{C}$ dia folha ${ }^{-1}$ ) (DELLAI et al., 2005), tomate $\left(14,2^{\circ} \mathrm{C}\right.$ dia folha${ }^{1}$ a $16,9^{\circ} \mathrm{C}$ dia folha ${ }^{-1}$ ) (PIVETTA et al., 2007) e calêndula $\left(15,9^{\circ} \mathrm{C}\right.$ dia folha ${ }^{-1}$ a $24,5^{\circ} \mathrm{C}$ dia folha $\left.{ }^{-1}\right)$ (KOEFENDER et al., 2008).

Em uma interpretação dos resultados de filocrono, considerando a fase final de muda (cerca de vinte folhas emitidas), a cultivar 'MGS ASC315' atingiu este patamar aos $519^{\circ} \mathrm{C}$ dia, na época de aclimatação 1 , e, aos $1125^{\circ} \mathrm{C}$ dia, na época de aclimatação 5. Já a cultivar 'Arbequina' atingiu esste mesmo patamar em torno dos $594,7^{\circ} \mathrm{C}$ dia (média das cinco épocas). Essa diferença de STa ( ${ }^{\circ} \mathrm{C}$ dia) entre as duas cultivares pode representar vários dias do calendário civil, especialmente quando a temperatura do ar é baixa, menor que $15^{\circ} \mathrm{C}$, comum de ocorrer na região Sul de Minas Gerais. Certamente, além de auxiliar no conhecimento do desenvolvimento da cultura da oliveira, esse tipo de informação é fundamental para o planejamento da implantação e do manejo dela no campo.

\section{CONCLUSÃO}

O desenvolvimento da oliveira na fase de muda foi quantificado através do conceito do filocrono. O filocrono foi maior nas épocas que apresentaram temperaturas mais elevadas para a cultivar 'Arbequina', situação comum de ocorrer. Para a 'MGS ASC315', o filocrono variou com a época de aclimatação, sendo menor nas épocas com temperaturas mais frias e maior nas épocas com temperaturas mais elevadas, situação contrária à maioria das culturas. Assim, em estudos futuros, outros métodos de cálculo de soma térmica podem ser utilizados para estimar o filocrono. Além disso, novos experimentos devem ser realizados a fim de verificar a influência de outros fatores, como o fotoperíodo, na estimativa deste.

\section{AGRADECIMENTOS}

À Coordenação de Aperfeiçoamento de Pessoal de Nível Superior (CAPES), pela bolsa de mestrado concedida, e à Empresa de Pesquisa Agropecuária de Minas Gerais (EPAMIG), pela infraestrutura disponibilizada.

\section{REFERÊNCIAS}

ARNOLD, C.Y. Maximum-minimum temperatures as a basis for computing heat units. American Society for Horticultural Science, Boston, v.76, n.1, p.682-692, 1960.

DELLAI, J. et al. Filocrono em diferentes densidades de plantas de batata. Ciência Rural, Santa Maria, v.35, n.6, p.1269-
1274, 2005. Disponível em: <http://www.scielo.br/pdf/cr/ v35n6/a07v35n6.pdf>. Acesso em: 6 dez. 2011. doi: 10.1590/ S0103-84782005000600007

FAGUNDES, J.D. et al. Crescimento, desenvolvimento e retardamento da senescência foliar em girassol de vaso (Helianthus annuus L.): fontes e doses de nitrogênio. Ciência Rural, Santa Maria, v.37, n.4, p.987-993, 2007. Disponível em: <http://www.scielo.br/pdf/cr/v37n4/a11v37n4.pdf>. Acesso em: 6 dez. 2011. doi: 10.1590/S0103-84782007000400011.

FERREIRA, D.F. Sisvar: a computer statistical analysis system. Ciência e Agrotecnologia, Lavras, v.35, n.6, p.1039-1042, 2011. Disponível em: <http://www.scielo.br/pdf/cagro/v35n6/ a01v35n6.pdf $>$. Acesso em: 20 jan. 2012. doi: 10.1590/S141370542011000600001 .

INTERNATIONAL OLIVE COUNCIL. Market newsletter. Madrid, 2011. Disponível em: <http://www.internationaloliveoil.org/>. Acesso em: 29 nov. 2011.

KOEFENDER, J. et al. Estimativa do filocrono em calêndula. Ciência Rural, Santa Maria, v.38, n.5, p.1246-1250, 2008. Disponível em: <http://www.scielo.br/pdf/cr/v38n5/a07v38n5.pdf>. Acesso em: 6 dez. 2011. doi: 10.1590/S0103-84782008000500007.

MARTINS, F.B. et al. Estimativa da temperatura-base para emissão de folhas e do filocrono em duas espécies de eucalipto na fase de muda. Revista Árvore, Viçosa, v.31, n.3, p.373381, 2007. Disponível em: <http://www.scielo.br/pdf/rarv/ v31n3/02.pdf>. Acesso em: 6 dez. 2011. doi: 10.1590/S010067622007000300002 .

MELO-ABREU, J.P. et al. Modelling olive flowering date using chilling for dormancy release and thermal time. Agricultural and Forest Meteorology, Amsterdam, v.125, n.1-2, p.117127, 2004. Disponível em: <http://www.sciencedirect.com/ science/article/pii/S016819230400070X>. Acesso em: $6 \mathrm{dez}$. 2011. doi: 10.1016/j.agrformet.2004.02.009.

OLIVEIRA, A.F. et al. Estaquia de oliveira em diferentes épocas, substratos e doses de AIB diluído em $\mathrm{NaOH}$ e álcool. Ciência e Agrotecnologia, Lavras, v.33, n.1, p.79-85, 2009. Disponível em: <http://www.scielo.br/pdf/cagro/v33n1/ v33n1a11.pdf $>$. Acesso em: 20 jan. 2012. doi: 10.1590/S141370542009000100011 .

OLIVEIRA, M.C. et al. Características fenológicas e físicas e perfil de ácidos graxos em oliveiras no sul de Minas Gerais. Pesquisa Agropecuária Brasileira, Brasília, v.47, n.1, p.3035, 2012.

PAULA, G.M.; STRECK, N.A. Temperatura base para emissão de folhas e nós, filocrono e plastocrono das plantas daninhas papuã e corriola. Ciência Rural, Santa Maria, v.38, n.9, p.2457-2463, 2008. Disponível em: <http://www.scielo.br/pdf/ cr/v38n9/a32cr556.pdf>. Acesso em: 6 dez. 2011. doi: 10.1590/ S0103-84782008005000032.

PIO, R. et al. Enraizamento de diferentes tipos de estacas de oliveira (Olea europaea L.) utilizando ácido indolbutírico. Ciência e Agrotecnologia, Lavras, v.29, n.3, p.562-567, 2005. Disponível em: <http://www.scielo.br/pdf/cagro/v29n3/ a08.pdf $>$. Acesso em: 20 jan. 2012. doi: 10.1590/S141370542005000300008 . 
PIVETTA, C.R. et al. Emissão e expansão foliar em três genótipos de tomateiro (Lycopersicon esculentum Mill.). Ciência Rural, Santa Maria, v.37, n.5, p.1274-1280, 2007. Disponível em: <http:/ /www.scielo.br/pdf/cr/v37n5/a09v37n5.pdf>. Acesso em: $6 \mathrm{dez}$. 2011. doi: 10.1590/S0103-84782007000500009.

ROSA, H.T. et al. Métodos de soma térmica e datas de semeadura na determinação de filocrono de cultivares de trigo. Pesquisa Agropecuária Brasileira, Brasília, v.44, n.11, p.1374-1382, 2009. Disponível em: <http://www.scielo.br/pdf/pab/v44n11/ 02.pdf>. Acesso em: 6 dez. 2011. doi: 10.1590/S0100204X2009001100002.

SCHONS, A. et al. Emissão de folhas e início de acumulação de amido em raízes de uma variedade de mandioca em função da época de plantio. Ciência Rural, Santa Maria, v.37, n.6, p.1586-1592, 2007. Disponível em: <http://www.scielo.br/pdf/ cr/v37n6/a13v37n6.pdf>. Acesso em: 6 dez. 2011. doi: 10.1590/S0103-84782007000600013.

SCOTT, A.J.; KNOTT, M. A cluster analysis method for grouping means in the analysis of variance. Biometrics, Washington, v.30, n.3, p.507-512, 1974. Disponível em: <http:/ /www.ime.usp.br/ abe/lista/pdfXz71qDkDx1.pdf>. Acesso em: 15 abr. 2012.
STATISTICAL GRAPHICS CORPORATION. Statgraphics Plus (2.1). Statistical Graphics Corporation. Rendón, Virginia, USA, 1999. (Programa estatístico).

STRECK, N.A. et al. Temperatura base para aparecimento de folhas e filocrono da variedade de milho BRS Missões. Ciência Rural, Santa Maria, v.39, n.1, p.224-227, 2009. Disponível em: <http://www.scielo.br/pdf/cr/v39n1/a35v39n1.pdf>. Acesso em: 6 dez. 2011. doi: 10.1590/S0103-84782009000100035.

VIEIRA NETO, J. et al. Aspectos técnicos da cultura da oliveira. Belo Horizonte: EPAMIG, 2008. 56p. (Boletim Técnico, 88).

VIEIRA NETO, J. et al. Desempenho de jardins clonais de oliveira (Olea europaea L.) em cortes sucessivos visando a sua propagação por estaquia. Revista Cerne, Lavras, v.17, n.1, p.117-122, 2011. Disponível em: <http://www.dcf.ufla.br/cerne/ administracao/publicacoes/m515v17n1o14.pdf $>$. Acesso em: 6 dez. 2011.

XUE, Q. et al. Predicting leaf appearance in field-grown winter wheat: evaluating linear and non-linear models. Ecological Modeling, Amsterdam, v.175, n.3, p.261-270, 2004. Disponível em: <http://www.sciencedirect.com/science/article/ pii/S0304380003004800>. Acesso em: 6 dez. 2011. doi: 10.1016/j.ecolmodel.2003.10.018. 